\title{
Consumption of Dietary Folate Estimates and Its Implication for Reproductive Outcome among Women of Reproductive Age in Kersa: Cross- Sectional Survey
}

\section{Nega Assefa}

Haramaya University

Yasir Y Abdullahi ( $\nabla$ yasdire@gmail.com )

Jugal Hospital

Aklilu Abrham

Haramaya University

Elena C Hemler

Harvard T.H. Chan School of Public Health, Harvard University

Isabel Madzorera

Harvard T.H. Chan School of Public Health, Harvard University

Yadeta Dessie

Haramaya University

Kedir Teji

Haramaya University

Wafaie W Fawzi

Harvard T.H. Chan School of Public Health, Harvard University

\section{Research Article}

Keywords: folate consumption, dietary folate, food diversity, daily folate consumption

Posted Date: June 18th, 2021

DOI: https://doi.org/10.21203/rs.3.rs-601866/v1

License: (c) (i) This work is licensed under a Creative Commons Attribution 4.0 International License. Read Full License

Version of Record: A version of this preprint was published at BMC Nutrition on November 15th, 2021.

See the published version at https://doi.org/10.1186/s40795-021-00476-6. 


\section{Abstract}

Background: Dietary folate inadequacy is one the most common micronutrient deficiencies that causes neural tube defect (NTD) among infants in Sub-Saharan African countries. This study aims to determine the dietary intake of folate among women of reproductive age (WRA) of Kersa, Eastern Ethiopia.

Methods: A cross-sectional study took place among voluntary women that were selected from 1140 random households. Using a validated Food Frequency Questionnaire, participants weekly dietary intake history of Ethiopian foods and dietary folate intake was worked out. Statistical analysis was done at $95 \%$ confidence interval. Modified Poisson regression was used to identify factors that associated with dietary folate consumption

Result: The estimated median usual intake of folate was $170 \mathrm{ug} / \mathrm{d}$ (IQR: 118.3; 252.2) and about 33\% WRA had low folate intake and $73.9 \%$ were at risk for folate inadequacy. From the reported food groups, Beans and Peas, Starchy staples, and Vitamin-A rich dark-green leafy vegetables were the top three ranked foods that contributed much of the dietary folate. The following conditions were statistically related with dietary folate inadequacy; women's age, being in poor wealth index, low dietary diversity, having seasonal employment, and reliance on market food source.

Conclusions: We found that women's dietary intake of folate in Kersa is very low and cannot protect their offspring from having NTD. They could also potentially be predisposed poor health outcomes. Diversifying and fortification Ethiopian wheats and salts could decrease the burden of folate deficiency in the country.

\section{Background}

Folate is one of the naturally occurring essential micronutrients found in food [1]. Dietary sources of folate include green leafy vegetables, legumes, egg yolks, liver, and citrus fruits [2]. Folic acid is the synthetic form of the micronutrient and is found in dietary supplements, enriched foods, and pharmaceutical vitamins. Folate is vital for various metabolic functions, including cell division and reproduction, and DNA and RNA synthesis in the body [3]. Folate deficiency is however a severe public health problem, especially among disadvantaged groups in developing countries [4, 5]. Even though data on the overall global folate status for women of reproductive age (WRA) are limited with huge discrepancies, the estimated prevalence of folate deficiency was $>20 \%$ compared to $<5 \%$ in lower- and higher-income countries, respectively [6].

Folate deficiency in WRA has been linked to various complications during pregnancy. These include increased risk of maternal anemia, hypertensive disorder, abortion, bleeding, and cardiovascular disease $[7,8]$. Folate deficiency has also been commonly cited as a significant risk factor for developing neural tube defects (NTD) in the fetus [9-11]. NTDs are a group of congenital anomalies occurring when the spinal cord fails to develop properly in utero, and they can present as Spina Bifida or Anencephaly or both 
[12-15]. These conditions affect more than 300,000 babies worldwide, the majority in developing countries [6, 7, 9]. In Ethiopia, it estimated that 65 infants out of 10,000 births have NTD [16].

There is limited data available on dietary folate intake from sub-national studies in sub-Saharan African (SSA) countries. In South Africa, the mean dietary folate intake for WRA was reported as 82 to $334 \mathrm{ug} / \mathrm{d}$ and median dietary folate intake for WRA in Ethiopia is estimated to be 88 to $204 \mu \mathrm{g} / \mathrm{d}$ [5]. It is also estimated around $98 \%$ and $100 \%$ of WRA have inadequate dietary folate intake in these counties $[5,8$, 17]. Folate intakes are often low among women in SSA because access to micronutrient-rich foods and fortified foods is limited, and these foods are expensive, locally unavailable, or unacceptable for cultural or religious reasons [18].

Given that inadequate dietary folate consumption is one of the primary causes of folate deficiency, the World Health Organization (WHO) recommends supplementation with $400 \mu \mathrm{g}$ of folic acid before pregnancy to decrease the incidence of NTD $[19,20]$. Ethiopia has relied on free distribution of iron and folic acid (IFA) tablets to pregnant women during antenatal care to address issues of folate deficiency [21]. Since the development of the central nervous system in the embryo occurs as early as nine weeks after fertilization, an increment in pre-pregnancy folate levels is the crucial and most appropriate method of reducing NTD and other pregnancy complications due to folate deficiency [22].Thus current approaches for IFA supplementation in Ethiopia and other SSA countries where most pregnant women present at health centers well advanced into the pregnancy will not address the problem.[23] Populationwise increment of folate consumption status by fortification of wheat and cereals and availing affordable nutrient-rich food alternatives and eliminating hunger have shown significantly in improving nutritional and the health status of women and their offspring $[24,25]$. However, there is limited availability of folate fortified foods or enriched food products in Ethiopia [26].

There is limited information available on the dietary intake of folate among WRA in Ethiopia. This study aims to evaluate dietary folate consumption among WRA in Kersa district of Oromia region, eastern Ethiopia. Further, the study evaluates dietary diversity, and other factors associated with folate consumption.

\section{Methods}

\section{Study area}

This study was conducted in the Kersa Health and Demographic Surveillance System (KHDSS) field site in Oromia region in eastern Ethiopia. The HDSS covers 24 kebeles (the lowest administrative unit in Ethiopia) three of which are urban, out of the 38 kebeles in the district. The 2016 national census reported that Kersa had the third largest in Oromia region with a total population of 350,064 , and a population density of36.8 persons per square kilometre [27].

We conducted a cross-sectional survey among 1200 households in the KHDSS from September to August, 2019 [28]. Study participants were selected using proportional allocation to the population size of 
the study kebeles, followed by random selection of households based on data from the KHDSS database. Eligibility criteria for the study included households with at least one married woman, who was of reproductive age (15-49 years old), and was not pregnant at study recruitment. If more than one woman of reproductive age lived in the household and was present at the time of interview, a lottery method was used to select one woman for the interview.

Data were collected via interviewer-administered tablet-based questionnaires. Women responded to a questionnaire, including information on socio-demographic characteristics, health information, food choices and cooking practices, food security, food expenditures, nutrition knowledge, homestead food production, and dietary intake. Height and weight of WRA were measured in the nearest centimeters $(\mathrm{cm})$ and kilograms (kg) using a stadiometer and standard clinical scale. [29]. Body mass index (BMI) was computed as weight in kilograms divided by height in meters squared. Based on BMI, individuals were classified using standard cutoffs as underweight $\left(<18.5 \mathrm{~kg} / \mathrm{m}^{2}\right)$, average weight $\left(18.5-24.9 \mathrm{~kg} / \mathrm{m}^{2}\right)$, or overweight/obese $\left(\geq 25 \mathrm{~kg} / \mathrm{m}^{2}\right.$ ). Overweight was classified as BMI $25-29.9 \mathrm{~kg} / \mathrm{m}^{2}$, and obesity BMI $\geq 30$ $\mathrm{kg} / \mathrm{m}^{2}[30]$.

Ethical approval for the study was obtained from the Institutional Health Research Ethical Review Board of the College of Health and Medical Sciences of Haramaya University in Ethiopia. At the time of visit to the household, written informed, voluntary consent was secured from respondents.

\section{Dependent variables:}

The outcome of interest was women's dietary folate intake. Women's diets were assessed using a nonquantitative food frequency questionnaire (FFQ), locally adapted from a semi-quantitative FFQ validated for use among urban Tanzanian adults [31]. The participants were asked if they consumed 69 different foods items in the past seven days and the frequency of their consumption in terms of days. The weekly reported consumption of the food items was converted into daily consumption by dividing by seven. The FFQ included locally available common foods and an option to specify other foods. Portion size information was not collected in the current study. We used portion sizes for each food item that were adopted from a recent national survey [32].

We estimated women's daily folate consumption by multiplying the mean portion size and folate composition for each reported food item with its daily consumption. We summed up women's total folate intake based on the reported individual foods in the FFQ. The cutoffs for inadequate folate intake were defined as consuming less than the age- and sex-specific Estimated Average Requirement (EAR) of folate intake of WRA $<250 \mu \mathrm{g} / \mathrm{d}$ [33]. We calculated a binary indicator for adequate folate intake (yes/no). We have also divided the total distribution of folate intake into tertiles and categorized them into low, middle, and high folate intake, respectively.

\section{Independent variables}

We considered women's dietary diversity and socio-demographic characteristics, including BMI, household family size and wealth index, household food source and pregnancy history as potential 
predictors of women's folate intake.

We assessed women's dietary diversity using the Minimum Dietary Diversity for Women (MDD-W) indicator [34]. We grouped foods consumed by women into ten non-overlapping food groups. The 10 food groups are 1) starchy staples, 2) pulses 3) nuts and seeds 4) dairy products 5) flesh foods 6 ) eggs 7) dark green leafy vegetables 8) vitamin-a rich fruits and vegetables 9) other vegetables and 10) other fruits [35]. Foods made from grains, cereals, roots, and tubers are grouped to starchy staples. Poultry and all meat products were categorized as flesh foods [36].

A participant was scored as consuming a food group if they ate at least one type of food item comprising that food group daily on average. We summed up the food groups consumed by women into a dietary diversity score (DDS-W, range $0-10$ ). We categorized women as meeting minimum dietary diversity $(M D D)$ if they consumed at least 5 food groups (DDS $\geq 5$ ) daily. MDD-W serves as a proxy for micronutrient adequacy [37].

We considered the following as potential predictors of women's folate intake. Women's BMI categorized as underweight, normal and over-weight. As the study setting was rural we classified women's employment according to the Ethiopian Demographic and health survey definition, as fully-employed, and seasonal and part-time employment [38]. Those who were fully employed had a skilled and stable job working in the 7 days preceding the survey. Hard labor and agricultural employment were categorized as partial and seasonal based on time and experience before the survey. Household wealth was defined using a wealth index, constructed using principal component analysis (PCA) of 10 items describing the household's asset ownership, housing quality, crowding, and water and sanitation facilities. The wealth index was divided into population tertiles (poor, middle, and rich) [39].

\section{Data processing and analysis}

Means, and standard deviations (SDs) were used to describe continuous variables and medians and interquartile ranges for variables that were not normally distributed. Counts and percentages were used to describe categorical variables. Data points with more than $50 \%$ missing data and with un-usual amounts (outliers) were removed from the analysis. Bivariate analysis using Modified Poisson regression [40, 41] was undertaken to examine the independent predictors of inadequate folate intake $(0=$ adequate consumption, 1 = inadequate consumption) and Crude Prevalence Ratios (CPR) and 95\% Confidence Interval $(\mathrm{Cl})$ estimated. Variables that were significant in the univariate analysis $(p<0.2)$ were included to control for confounding for the final model. We adjusted Prevalence Ratio (APR) by incorporating variables that are significant or assumed to be a confounder. The statistical association level was $p<$ 0.05 to identify independent variables associated with inadequate folate consumption.

\section{Results}

We analyzed data from 1134 WRA household that participated in the study. Thirty-nine households refused to participate in the study and 27 participants with missing and outlier data were excluded from 
the analysis. The mean age of women was $31.1( \pm 6.2)$ years and a half of the women had never attended school. Most participants were Muslims and housewives. At least $67.5 \%$ of WRA worked worked full time and $56.2 \%$ were in the poor wealth index category. The median weight and height of WRA was $51.0 \mathrm{~kg}$ (IQR: $48.0 ; 56.0)$ and $157.0 \mathrm{~cm}$ (IQR: 154.5; 161.1), respectively (Table 1). 
Table 1

Sociodemographic, reproductive, and Food intake characteristics of women of reproductive age in Kersa, Eastern Ethiopia, 2019

\begin{tabular}{|c|c|c|}
\hline Variables & $\mathbf{N}$ & Values \\
\hline Woman's age (years) & \multirow[t]{4}{*}{1134} & \\
\hline $16-25$ & & $268(23.6)$ \\
\hline $26-35$ & & $637(56.2)$ \\
\hline$\geq 36$ & & $229(20.2)$ \\
\hline Highest Education & \multirow[t]{4}{*}{1134} & \\
\hline Never attended school & & $609(50.7)$ \\
\hline Did not finished first grade & & $99(8.7)$ \\
\hline Completed 10 grade and more & & $426(37.6)$ \\
\hline Partner Highest Education & \multirow[t]{4}{*}{1134} & \\
\hline Never attended school & & $571(50.4)$ \\
\hline Did not finished first grade & & $84(7.4)$ \\
\hline Completed 10 grade and more & & $479(42.2)$ \\
\hline Religion & \multirow[t]{4}{*}{1134} & \\
\hline Muslim & & $1080(95.2)$ \\
\hline Orthodox & & $42(3.7)$ \\
\hline Other ${ }^{b}$ & & $12(1.1)$ \\
\hline Employment type & \multirow[t]{4}{*}{1134} & \\
\hline Full-time & & $765(67.5)$ \\
\hline Part-time & & $101(8.9)$ \\
\hline seasonal & & $268(23.6)$ \\
\hline Occupational status of women & \multirow[t]{5}{*}{1134} & \\
\hline Farmer & & $925(81.6)$ \\
\hline Trade & & $49(4.3)$ \\
\hline Professional/technical & & $66(5.8)$ \\
\hline Other ${ }^{d}$ & & $94(8.3)$ \\
\hline Role in the household & \multicolumn{2}{|l|}{1134} \\
\hline
\end{tabular}




\begin{tabular}{|c|c|c|}
\hline Variables & $\mathbf{N}$ & Values \\
\hline Head of the $\mathrm{HH}$ & & $141(12.4)$ \\
\hline Spouse & & $981(86.5)$ \\
\hline Another ${ }^{c}$ & & $14(1.1)$ \\
\hline Wealth index & \multirow[t]{4}{*}{1134} & \\
\hline Poor & & $637(56.2)$ \\
\hline Middle & & $265(23.4)$ \\
\hline Rich & & $232(20.4)$ \\
\hline Weight ${ }^{a}(\mathrm{~kg})$ & 1134 & $51.0(48.0 ; 56.0)$ \\
\hline Height ${ }^{a}(\mathrm{~cm})$ & 1134 & $157.0(154.5 ; 161.1)$ \\
\hline Body Mass Index (BMI) ${ }^{a}$ & 1134 & $20.6(19.2 ; 22.4)$ \\
\hline \multicolumn{3}{|l|}{ BMI } \\
\hline Underweight & 1134 & $188(16.6)$ \\
\hline Normal & & $870(76.7)$ \\
\hline Overweight & & $76(6.7)$ \\
\hline Family size $\#$ & 1134 & $5.8 \pm(3.0)$ \\
\hline Has an under 5 children & 1134 & $1029(90.7)$ \\
\hline Age of Under 5 children ${ }^{a *}$ & 1029 & $36.0(23.0 ; 48.0)$ \\
\hline Number of previous pregnancies \# & 1134 & $4.5 \pm(2.4)$ \\
\hline Source of household food & \multirow[t]{3}{*}{1134} & \\
\hline Household production & & $854(75.3)$ \\
\hline Street Vendor and local market & & $280(24.7)$ \\
\hline Food source Distance from Household \# e & 280 & $0.7 \pm(1.4)$ \\
\hline Women's Minimum dietary diversity scores (out of 10 groups) a f & 1134 & $4.0(3.0 ; 5.0)$ \\
\hline Minimum dietary diversity & \multirow[t]{2}{*}{1134} & \\
\hline Low & & $733(64.6)$ \\
\hline Estimated Usual Folate intake (ug/d) a & 1134 & $170.2(118.3 ; 252.2)$ \\
\hline
\end{tabular}




\begin{tabular}{|lll|}
\hline Variables & N & Values \\
\hline Estimated Folate inadequacy & 1134 & $838(73.9)$ \\
\hline Tertile of Folate Intake & 1134 & $378(33.33)$ \\
Low & $378(33.33$ \\
Middle & $378(33.33)$ \\
High & & \\
\hline Proportion of Low usual Folate intake & $378(33.3)$ \\
\hline Values are mean \pm SD, median [IQR], or frequency (percent). & & \\
\hline a $=$ Median (25th ; 75th percentile) & & \\
\hline \#= Mean $\mathbf{\text { (SD) }}$ & & \\
\hline b $=$ Protestant, Jehovah-witness & & \\
\hline c $=$ sister, daughter, aunt & & \\
\hline d $=$ unskilled and manual labor, clerical & \\
\hline e $=\mathbf{2 8 0}$ observations & \\
\hline * = age in Months & \\
\hline
\end{tabular}

Many of the participants reported using own food production as a primary source of food and travel more than half a kilometer for reaching the source. The median dietary diversity score was 4.0 (IQR: 3.0; 5.0) and $35.4 \%$ of had optimum dietary diversity (consumed 5 or more food groups daily). Most study participants had under-five children in their household with a median age of 36 months (IQR: 23.0; 48.0). The highest number of previous pregnancies reported was thirteen (Table 1).

\section{Food frequency distribution and food ranking}

Table 2 shows the ranking and contribution of food groups to the dietary intake of folate. Almost all participants reported consuming starchy staples and other vegetables but these groups ranked 2nd and 5 th in contributing to daily dietary folate intake. Even though less than half of the study participants reported intake of beans and peas, they were ranked the 1st in contributing dietary folate with median of $101.7 \mathrm{ug} / \mathrm{d}$ (IQR: 73.7; 178.3). The least consumed food group was flesh foods and it is also contributed least to folate intake. The median folate consumption in this study was $170.2 \mathrm{ug} /$ day (IQR: 118.3; 252.2): $95 \% \mathrm{Cl}(164.3-176.1)$. The distribution of folate intake was positively skewed and $73.9 \%$ were at risk for dietary folate inadequacy based on a cut-off of $250 \mu \mathrm{g} /$ day (Figs. 1 and 2). About 33\% of WRA had low folate intake. 
Page 10/23 
Table 2

Food frequency with Mean Folate dietary intake of women of reproductive age in Kersa, Eastern Ethiopia, 2019

\begin{tabular}{|c|c|c|c|c|}
\hline Food group & Rank & Contribution & Consumed & Folate (ug/d) * \\
\hline 1) All starchy staples & 2 & $49.6 \%$ & $\begin{array}{l}1130 \\
(99.6)\end{array}$ & $84.4(60.4 ; 104.0)$ \\
\hline Consumed everyday & & & $769(67.8)$ & $95.2(75.9 ; 110.4)$ \\
\hline Consumed $\leq 6$ days & & & $361(31.8)$ & $55.1(38.6 ; 72.4)$ \\
\hline 2) Beans and Peas & 1 & $59.7 \%$ & $467(41.2)$ & $\begin{array}{l}101.7(73.7 \\
178.3)\end{array}$ \\
\hline Consumed everyday & & & $16(1.4)$ & $\begin{array}{l}340.0(129.0 \\
342.3)\end{array}$ \\
\hline Consumed $\leq 6$ days & & & $451(39.8)$ & $97.1(73.7 ; 161.6)$ \\
\hline 3) Nuts and Seeds & 4 & $11.0 \%$ & $74(6.5)$ & $18.7(18.0 ; 27.0)$ \\
\hline Consumed everyday & & & $0.0(0.0)$ & $0.0(0.0 ; 0.0)$ \\
\hline Consumed $\leq 6$ days & & & $74(6.5)$ & $18.7(18.0 ; 27.0)$ \\
\hline 4) All Diary & 8 & $4.4 \%$ & $754(66.5)$ & $7.5(4.3 ; 7.5)$ \\
\hline Consumed everyday & & & $293(25.8)$ & $7.5(7.5 ; 7.5)$ \\
\hline Consumed $\leq 6$ days & & & $461(40.6)$ & $5.4(4.3 ; 6.9)$ \\
\hline 5) Flesh Foods & 10 & $1.0 \%$ & $119(10.5)$ & $1.7(0.9 ; 3.4)$ \\
\hline Consumed everyday & & & $4(0.4)$ & $6.0(6.0 ; 148.0)$ \\
\hline Consumed $\leq 6$ days & & & $115(10.1)$ & $1.7(0.9 ; 3.4)$ \\
\hline 6) Eggs & 9 & $3.1 \%$ & $134(11.8)$ & $5.3(2.6 ; 10.6)$ \\
\hline Consumed everyday & & & $2(0.2)$ & $18.5(18.5 ; 18.5)$ \\
\hline Consumed $\leq 6$ days & & & $132(11.6)$ & $5.3(2.6 ; 10.6)$ \\
\hline $\begin{array}{l}\text { 7) Vitamin A-rich dark green leafy } \\
\text { vegetables }\end{array}$ & 3 & $23.0 \%$ & $524(46.2)$ & $39.2(26.1 ; 52.3)$ \\
\hline Consumed everyday & & & $10(0.9)$ & $91.4(91.4 ; 91.4)$ \\
\hline Consumed $\leq 6$ days & & & $514(45.3)$ & $39.2(26.1 ; 52.3)$ \\
\hline $\begin{array}{l}\text { 8) Other vitamin A-rich vegetables and } \\
\text { fruits }\end{array}$ & 6 & $5.5 \%$ & 355 (31.3) & $9.4(6.0 ; 16.9$ \\
\hline Consumed everyday & & & $2(0.2)$ & $21.0(21.0 ; 21.0)$ \\
\hline
\end{tabular}




\begin{tabular}{|lllll|}
\hline Food group & Rank & Contribution & Consumed & Folate $(\mathbf{u g} / \mathbf{d})$ * \\
\hline Consumed $\leq 6$ day & & & $353(31.1)$ & $9.0(6.0 ; 16.3)$ \\
\hline 9) Other vegetables & 5 & $10.4 \%$ & $\begin{array}{l}1113 \\
(98.2)\end{array}$ & $17.7(15.5 ; 27.1)$ \\
\hline Consumed everyday & & & $890(78.5)$ & $17.7(15.5 ; 28.0)$ \\
\hline Consumed $\leq 6$ days & & & $223(19.7)$ & $15.5(11.9 ; 23.5)$ \\
\hline 10) Other fruits & 7 & $5.2 \%$ & $152(13.4)$ & $8.8(8.8 ; 23.1)$ \\
\hline Consumed everyday & & & $20(1.8)$ & $42.8(42.8 ; 42.8)$ \\
\hline Consumed $\leq 6$ days & & $132(11.6)$ & $8.8(8.8 ; 13.2)$ \\
\hline * Median Folate intake (25th ; 75th percentile) & & & \\
\hline
\end{tabular}

\section{Factors associated with dietary folate inadequacy}

Table 3 shows the factors associated with inadequate dietary folate consumption. We found that wealth index, seasonal employment, and low women's nutritional diversity were associated with inadequate folate intake defined as intake of below EAR of folate, which below $250 \mu \mathrm{g} /$ day in a population in univariate models. In adjusted models, seasonal employment, food source, being in the lowest and middle wealth index category, and low women's nutritional diversity were associated with dietary folate inadequacy. Women with low dietary diversity intake were twice as likely (APR 1.9; 95\% Cl 1.7-2.2) to have inadequate folate intake compared to women who met criteria for minimum dietary diversity. Women who were involved in seasonal agricultural employments were more likely (APR 1.1; 95\% Cl 1.11.2) to have inadequate folate intake compared to women with full-time employment. Compared to women in the wealthiest households, women from poor and middle wealth tertile were 1.1 times $(95 \% \mathrm{Cl}$ 1.0-1.3) and 1.2 times $(95 \% \mathrm{Cl} 1.1-1.4)$ more likely to have dietary folate inadequacy, respectively. Women aged $15-25$ years were $10 \%$ less likely to be at risk for folate inadequacy compared to those aged 36 years or older. 
Table 3

Factors associated with inadequate dietary folate consumption ${ }^{\mathrm{a}}$ among women of reproductive age in Kersa, eastern Ethiopia, 2019

\begin{tabular}{|c|c|c|c|c|c|c|c|}
\hline & $\begin{array}{l}\text { Inadequate } \\
\text { Folate N (\%) }\end{array}$ & CPR & $95 \% \mathrm{Cl}$ & $\begin{array}{l}\mathrm{P}- \\
\text { value }\end{array}$ & APR & $95 \% \mathrm{Cl}$ & P-value \\
\hline Age & $190(70.9)$ & 0.88 & \multirow{2}{*}{$\begin{array}{l}0.80- \\
0.97\end{array}$} & 0.01 & 0.89 & $\begin{array}{l}0.80- \\
0.97\end{array}$ & $0.01 * \star$ \\
\hline $16-25$ & $464(72.4)$ & 0.91 & & 0.02 & 0.96 & \multirow{3}{*}{$\begin{array}{l}0.89- \\
1.02\end{array}$} & 0.20 \\
\hline $25-35$ & $184(80.4)$ & ref & \multirow{2}{*}{$\begin{array}{l}0.84- \\
0.98\end{array}$} & & ref & & \\
\hline \multicolumn{6}{|l|}{$\geq 36$} & & \\
\hline Employment type & 547 (71.5) & ref & \multirow{4}{*}{$\begin{array}{l}0.73- \\
1.01 \\
1.12- \\
1.28\end{array}$} & & ref & $0.80-.1 .07$ & 0.30 \\
\hline Full-time & $62(61.4)$ & 0.86 & & 0.000 & 0.93 & \multirow{3}{*}{$\begin{array}{l}1.06- \\
1.20\end{array}$} & \multirow{3}{*}{$\begin{array}{l}< \\
0.001 * *\end{array}$} \\
\hline Part-time & $229(85.5)$ & 1.19 & & & 1.12 & & \\
\hline Seasonal & & & & & & & \\
\hline BMI & 149 (79.3) & 1.08 & \multirow{4}{*}{$\begin{array}{l}0.99- \\
1.17 \\
\text { ref } \\
0.74- \\
1.04\end{array}$} & 0.40 & 1.03 & \multirow{2}{*}{$\begin{array}{l}0.96- \\
1.11\end{array}$} & 0.4 \\
\hline Underweight & $640(73.6)$ & ref & & 0.58 & ref & & 0.6 \\
\hline Average & $49(64.5)$ & 0.88 & & & 0.97 & \multirow{2}{*}{$\begin{array}{l}\text { ref } \\
0.84- \\
1.11\end{array}$} & \\
\hline Overweight & & & & & & & \\
\hline Wealth Index & $513(80.5)$ & 1.39 & \multirow{2}{*}{$\begin{array}{l}1.24- \\
1.57\end{array}$} & 0.01 & 1.14 & \multirow{2}{*}{$\begin{array}{l}1.03- \\
1.26\end{array}$} & $0.01^{* \star}$ \\
\hline Poor & $191(72.1)$ & 1.25 & & 0.000 & 1.20 & & \multirow{2}{*}{$\begin{array}{l}< \\
0.001^{* *}\end{array}$} \\
\hline Middle & $134(57.8)$ & ref & $\begin{array}{l}1.09- \\
1.43\end{array}$ & & ref & $\begin{array}{l}1.06- \\
1.35\end{array}$ & \\
\hline Rich & & & \multicolumn{2}{|l|}{ ref } & & Ref & \\
\hline $\begin{array}{l}\text { Number of previous } \\
\text { pregnancies" }\end{array}$ & $4.54(2.44)$ & 1.02 & $\begin{array}{l}1.00- \\
1.03\end{array}$ & 0.03 & 0.99 & $\begin{array}{l}0.98- \\
1.01\end{array}$ & 0.7 \\
\hline Dietary Diversity & $180(44.9)$ & ref & ref & 0.000 & ref & ref & \multirow{3}{*}{$\begin{array}{l}<.001 * \star \\
0.00\end{array}$} \\
\hline Optimum & $658(89.8)$ & 2.00 & \multirow{2}{*}{\multicolumn{2}{|c|}{$\begin{array}{l}1.79- \\
2.23\end{array}$}} & 1.94 & \multirow[t]{2}{*}{$\begin{array}{l}1.73- \\
2.18\end{array}$} & \\
\hline Low & & & & & & & \\
\hline
\end{tabular}

$\mathrm{a}=$ folate intake of $<250 \mu \mathrm{g} /$ day

\# = mean (SD)

$\mathrm{CPR}=$ Crude Prevalence Ratio

APR = Adjusted Prevalence Ratio

** $=$ significant at $p=0.05$ 


\begin{tabular}{|c|c|c|c|c|c|c|c|}
\hline & $\begin{array}{l}\text { Inadequate } \\
\text { Folate N (\%) }\end{array}$ & CPR & $95 \% \mathrm{Cl}$ & $\begin{array}{l}\mathrm{P}- \\
\text { value }\end{array}$ & APR & $95 \% \mathrm{Cl}$ & P-value \\
\hline Food source & $622(72.8)$ & ref & ref & 0.2 & ref & ref & $0.04^{\star \star}$ \\
\hline Household & $216(77.1)$ & 1.06 & $\begin{array}{l}0.98- \\
1.14\end{array}$ & & 1.07 & $\begin{array}{l}1.01- \\
1.15\end{array}$ & \\
\hline Market & & & & & & & \\
\hline \multicolumn{8}{|c|}{$\mathrm{a}=$ folate intake of $<250 \mu \mathrm{g} /$ day } \\
\hline \multicolumn{8}{|c|}{$\#=$ mean $(S D)$} \\
\hline \multicolumn{8}{|c|}{$\mathrm{CPR}=$ Crude Prevalence Ratio } \\
\hline \multicolumn{8}{|c|}{ APR = Adjusted Prevalence Ratio } \\
\hline$\star \star=$ significa & & & & & & & \\
\hline
\end{tabular}

\section{Discussion}

This study assessed dietary folate intake among women of reproductive age in Kersa, Eastern Ethiopia. Most participants had low dietary diversity during the study period, with most consuming starchy stables and vegetables. The food groups least consumed were fish, eggs, fleshy-foods, and fruits. Many women had folate intake which was insufficient and far less than the recommended standard of $250 \mathrm{ug} / \mathrm{d}$,.[33]. We found that women that had low dietary diversity, in poorer households, seasonal employment and market purchases of food were at higher risk of dietary folate inadequacy. Oder women were also more like to have inadequate dietary folate intake.

We found low levels of folate intake, which was $33 \%$ and high magnitude of folate inadequacy for WRA in Kersa. In this study, the folate inadequacy was higher compared to Tanzania which was $33.8 \%$, but comparable with the low intake folate, which was 33\% [42]. It was also higher than in Nigerian study, where $47 \%$ had inadequate intake but lower than in South African report of $98 \%$ [5]. The difference could be related to the difference in utilizing different methodology, food stability and security in those different countries. In developed countries, it was previously reported having a folate inadequacy of $64 \%[12,43]$. These counties had decreased folate deficiency and the incidence of NTD by fortifying primary foods that would typically have no or little folate $[9,42,44]$ In those countries not only mandatory folate fortification policies are in place, but also improving in dietary diversity, gender equity and equality $[6,14,45]$ unlike Ethiopia, explaining the higher folate deficiency in our population. It is estimated that mandatory fortification in Ethiopia will reduce NTD by $85 \%$ annually if fully implemented [46]. Although effective, the policy has not been endorsed and developed in Ethiopia [47].

The high magnitude of dietary folate inadequacy is expected and could be related to the characteristics of the study area. With reliance on supplementation of folic acid in pregnancy, WRA would at risk for 
folate deficiency. It is also one of drought prone, with poor living standard, difficulty in accessing affordable folate rich foods and poor place of Ethiopia. Most of the dietary system is mainly based on traditional farming in unsuitable places, with poor support from the agriculture system. As a result, most of the residents are supported through the safety-net program [48].

Even though the serum level of folate was not measured, our study showed a close relationship between dietary diversity and folate inadequacy. Daily folate-rich food like beans and peas were consumed by less than half of the participants but it contributed the most folate from all food groups. Whereas the starchy stables and vegetables were consumed daily, the amount of folate was lower compared to intake of fleshy foods (including liver), where only four women reported its intake in one week before the data collection. This finding agrees with much of the scientific literature that stated dietary inadequacy being the primary cause of folate deficiency $[14,49]$.

We found that with an increase in women's age was more likely to be inadequacy of dietary folate. Another cross-sectional FFQ study reported younger women were more likely to have folate inadequacy than advanced-aged women [7]. This difference could be respectively be explained by the higher house hold family member and children the older women expected to feed [7]. The study finding could also be limited by the potential introduction of recall bias and participants could over-report the consumption of specific food items.

Seasonal agricultural employment and being in a poor and middle category of wealth were also associated with dietary folate intake insufficiency. This finding is expected because women's seasonal dependent agricultural employment could have a potential for hunger and food scarcity and insecurity for families due to lack of other options if difficulties arise for harvest or drought seasons [50]. Besides, seasonal agricultural employment also leads to poverty, which in-turn poses makes it difficult to purchase adequate nutrient rich-food for the family [51]. The risk of folate dietary inadequacy increased in twice in women who had low dietary diversity compared to their counterparts. This finding can be attributed to the fact that having low dietary diversity leads to unhealthy and unbalanced diet patterns as well as micronutrient deficiencies [52]. WRA in Ethiopia relatively eat less because food shortage, physical discomfort, and unpleasant monotonous food with less variety [17]. This puts them at increased risk for any micronutrient deficiency in a household. Other studies in Ethiopia have also reported dietary diversity was a strong predictor of micronutrient adequacies with direct relationship with food security, household income and health access of a community $[53,54]$

Ethiopia is one the highest NTD burdened country, with a prevalence rate ranging from $0.23 \%-40.3 \%$ [ 55 , 56]. For pregnant women, reports indicate $12 \%$ folate deficiency in Ethiopia, $3 \%$ in Kenya, and $4 \%$ in Nigeria [5]. Other causes for folate deficiency include low bio-activity, pregnancy, malabsorptive conditions, anti-folate drugs or other metabolic inhibitors, and alcohol intake $[4,57]$ Low levels of folate consumption reported in this study can affect nutrition and health for WRA. Given that low folate intake can affect cell growth and duplication [58]. Low intake among WRA prior to and during pregnancy could lead to irreversible damage to the nerve system of the conceived fetus [59]. The nerve damage to the 
baby ranges from a complete loss of fetal brain to some defects in the brain, spinal cord, and associated structures (ref). Anencephaly and spina bifida are common condition attributed for low level of folate concentration in the women's body. In any case of these, the outcome is clear, either the fetus will die or born with a permanent neural damage leading to a lifelong disability affecting growth, development, and failure to thrive [60].

To correct the problem, in the routine health system, pregnant women are given a capsule that contain iron and folic acid for ninety days. Yet, it is reported that, only as few as five percent of the women complete the full doses and the remaining more than $95 \%$ leave their fetus to the mercy of dietary folate consumption [21, 61]. In-addition, the widely available foods in Ethiopia have low bioavailable folate. Even though it is planned in introducing Folic Acid intervention program in our national document like fortification, it is not implemented [32]

Some of the strength of this study is utilizing the first community based FFQ with adequate sample size and training data collectors for quality control. The utilization of FFQ is a quick and efficient way of identifying and assessing micronutrient inadequacy. A past-week FFQ can provide better assessment of usual intake of micronutrient intake compared to 24- hour recall [62]. However, it has also several limitations. FFQ usually overestimate micronutrient intake which made it difficult in accurately capturing absolute micronutrient value and introduces with and between variation errors [63]. To reduce this, we have seen the folate intake distribution using two different cut-offs, the EAR ( $<250 \mu \mathrm{g} / \mathrm{d})$ and tertiles. Other factors that may affect folate absorption, seasonal dietary changes, knowledge, and awareness towards folate were not considered in this study.

\section{Conclusion}

The study found that folate intake is low and that folate inadequacy is public health in Kersa, Eastern Oromia. Diversifying diets, and daily consumption of folate-rich foods like beans and liver, and mandatory fortification of wheat or salt are highly recommended to increase folate adequacy and decrease risk of folate deficiency among WRA. National FFQ coupled with plasma folate levels are recommended for accurate identification of folate inadequacy and deficiency as well as for monitoring of micronutrient deficiencies

\section{Abbreviations}

DDS; dietary diversity score;

FFQ; food frequency questionnaire,

IFA; iron and folic acid,

MDD; minimum dietary diversity, 
NTD; neural tube defect,

PSA; principal component analysis,

SSA; Sub-Saharan Africa,

WRA; women of reproductive age,

\section{Declarations}

\section{Ethics Approval and consent to participate}

This study was ethically cleared by Institution Health Research Ethical Review Board of the College of Health and Medical Sciences with reference number SHE/S1M/14.4/708/19 and the procedures were undertaken in accordance to Helenski Declaration

\section{Consent for publication}

Not Applicable

\section{Availability of data and materials}

The datasets used and analyzed during this study are available from the corresponding author on reasonable request

\section{Competing Interest}

The authors declare no conflicts of interest.

\section{Funding}

This work was supported Harvard T.H. Chan School of Public Health, USA.

\section{Acknowledgements}

The Authors wish to Thank Dr Sabri Bromage for his valuable comments and suggestions and Harvard school of public health for their assistance in data collection. The authors would like to thank study participants, local administrators, and data collector in facilitating the data collection.

\section{References}


1. Gazzali AM, Lobry M, Colombeau L, Acherar S, Azais H, Mordon S, Arnoux P, Baros F, Vanderesse R, Frochot C: Stability of folic acid under several parameters. Eur J Pharm Sci 2016, 93:419-430.

2. Evans SE, Mygind VL, Peddie MC, Miller JC, Houghton LA: Effect of increasing voluntary folic acid food fortification on dietary folate intakes and adequacy of reproductive-age women in New Zealand. Public Health Nutr 2014, 17:1447-1453.

3. van Gool JD, Hirche H, Lax H, De Schaepdrijver L: Folic acid and primary prevention of neural tube defects: A review. Reprod Toxicol 2018, 80:73-84.

4. Nunn RL, Kehoe SH, Chopra H, Sahariah SA, Gandhi M, Di Gravio C, Coakley PJ, Cox VA, Sane H, Shivshankaran $D$, et al: Dietary micronutrient intakes among women of reproductive age in Mumbai slums. Eur J Clin Nutr 2019, 73:1536-1545.

5. Harika R, Faber M, Samuel F, Kimiywe J, Mulugeta A, Eilander A: Micronutrient Status and Dietary Intake of Iron, Vitamin A, lodine, Folate and Zinc in Women of Reproductive Age and Pregnant Women in Ethiopia, Kenya, Nigeria and South Africa: A Systematic Review of Data from 2005 to 2015. Nutrients 2017, 9.

6. Rogers LM, Cordero AM, Pfeiffer CM, Hausman DB, Tsang BL, De-Regil LM, Rosenthal J, Razzaghi H, Wong EC, Weakland AP, Bailey LB: Global folate status in women of reproductive age: a systematic review with emphasis on methodological issues. Ann N Y Acad Sci 2018, 1431:35-57.

7. Rodrigues HG, Gubert MB, Santos LM: Folic acid intake by pregnant women from Vale do Jequitinhonha, Brazil, and the contribution of fortified foods. Arch Latinoam Nutr 2015, 65:27-35.

8. Arias LD, Parra BE, Munoz AM, Cardenas DL, Duque TG, Manjarres LM: Study Exploring the Effects of Daily Supplementation with $\mathbf{4 0 0}$ mug of Folic Acid on the Nutritional Status of Folate in Women of Reproductive Age. Birth Defects Res 2017, 109:564-573.

9. Centeno Tablante E, Pachon H, Guetterman HM, Finkelstein JL: Fortification of wheat and maize flour with folic acid for population health outcomes. Cochrane Database Syst Rev 2019, 7:CD012150.

10. Bulloch RE, McCowan LME, Thompson JMD, Houghton LA, Wall CR: Plasma folate and its association with folic acid supplementation, socio-demographic and lifestyle factors among New Zealand pregnant women. Br J Nutr 2019, 122:910-918.

11. McNulty H, Ward M, Hoey L, Hughes CF, Pentieva K: Addressing optimal folate and related B-vitamin status through the lifecycle: health impacts and challenges. Proc Nutr Soc 2019, 78:449-462.

12. French MR, Barr SI, Levy-Milne R: Folate intakes and awareness of folate to prevent neural tube defects: a survey of women living in Vancouver, Canada. J Am Diet Assoc 2003, 103:181-185.

13. Meng Q, Zhang L, Liu J, Li Z, Jin L, Zhang Y, Wang L, Ren A: Dietary folate intake levels in rural women immediately before pregnancy in Northern China. Birth Defects Res A Clin Mol Teratol 2015, 103:27-36.

14. Karacil Ermumcu MS, Mengi Celik O, Acar Tek N: An Evaluation of Awareness, Knowledge, and Use of Folic Acid and Dietary Folate Intake among Non-Pregnant Women of Childbearing Age and Pregnant Women: A Cross-Sectional Study from Turkey. Ecol Food Nutr 2020:1-15. 
15. Centers for Disease C, Prevention: Trends in folic acid supplement intake among women of reproductive age-California, 2002-2006. MMWR Morb Mortal Wkly Rep 2007, 56:1106-1109.

16. Bitew ZW, Worku T, Alebel A, Alemu A: Magnitude and Associated Factors of Neural Tube Defects in Ethiopia: A Systematic Review and Meta-Analysis. Glob Pediatr Health 2020, 7:2333794X20939423.

17. Asayehu TT, Lachat $C$, Henauw S, Gebreyesus SH: Dietary behaviour, food and nutrient intake of women do not change during pregnancy in Southern Ethiopia. Matern Child Nutr 2017, 13:e12343.

18. Sayed AR, Bourne D, Pattinson R, Nixon J, Henderson B: Decline in the prevalence of neural tube defects following folic acid fortification and its cost-benefit in South Africa. Birth Defects Res A Clin Mol Teratol 2008, 82:211-216.

19. Amoroso L: The Second International Conference on Nutrition: Implications for Hidden Hunger. World Rev Nutr Diet 2016, 115:142-152.

20. World Health Organization (WHO), Food and Agriculture Organization (FAO): Vitamin and mineral requirements in human nutrition. 2 edn. Geneva: WHO; 2004.

21. Desta M, Kassie B, Chanie H, Mulugeta H, Yirga T, Temesgen H, Leshargie CT, Merkeb Y: Adherence of iron and folic acid supplementation and determinants among pregnant women in Ethiopia: a systematic review and meta-analysis. Reprod Health 2019, 16:182.

22. Obeid R, Oexle K, Rissmann A, Pietrzik K, Koletzko B: Folate status and health: challenges and opportunities. J Perinat Med 2016, 44:261-268.

23. Gomes S, Lopes $\mathrm{C}$, Pinto E: Folate and folic acid in the periconceptional period: recommendations from official health organizations in thirty-six countries worldwide and WHO. Public Health Nutr 2016, 19:176-189.

24. Gaskins AJ, Mumford SL, Chavarro JE, Zhang C, Pollack AZ, Wactawski-Wende J, Perkins NJ, Schisterman EF: The impact of dietary folate intake on reproductive function in premenopausal women: a prospective cohort study. PLoS One 2012, 7:e46276.

25. Gaskins AJ, Minguez-Alarcon L, Fong KC, Abu Awad Y, Di Q, Chavarro JE, Ford JB, Coull BA, Schwartz J, Kloog I, et al: Supplemental Folate and the Relationship Between Traffic-Related Air Pollution and Livebirth Among Women Undergoing Assisted Reproduction. Am J Epidemiol 2019, 188:1595-1604.

26. USAID: Feed The Future: Ethiopia's Growth through Nutrition project In The US Goverment's Global Hunger \& Food Security Initiative2019.

27. Oromiya: Demography and Health [http://www.ethiodemographyandhealth.org/Oromia.html] 28. Assefa N, Oljira L, Baraki N, Demena M, Zelalem D, Ashenafi W, Dedefo M: HDSS Profile: The Kersa Health and Demographic Surveillance System. Int J Epidemiol 2016, 45:94-101.

29. Bilukha O, Leidman E: Concordance between the estimates of wasting measured by weight-for-height and by mid-upper arm circumference for classification of severity of nutrition crisis: analysis of population-representative surveys from humanitarian settings. BMC Nutrition 2018, 4:24-24.

30. WHO (World Health Organization): Body Mass Index - BMI. 2019. 
31. Zack RM, Irema K, Kazonda P, Leyna GH, Liu E, Gilbert S, Lukmanji Z, Spiegelman D, Fawzi W, Njelekela M, et al: Validity of an FFQ to measure nutrient and food intakes in Tanzania. Public Health Nutr 2018, 21:2211-2220.

32. Ethiopian Public Health Institute: Ethiopian national food consumption survey. Addis Ababa, Ethiopia2013.

33. Allen LH, Carriquiry AL, Murphy SP: Perspective: Proposed Harmonized Nutrient Reference Values for Populations. Adv Nutr 2020, 11:469-483.

34. Wiesmann $D$, Arimond $M$, Loechi $C$ : Dietary diversity as a measure of the micronutrient adequacy of women's diets: Results from rural Mozambique site. In Washington (DC): Food and Nutrition Technical Assistance II Project, FHI 3602009.

35. FAO, FHI 360: Minimum dietary diversity for women: a guide for measurement. vol. 82. Rome: FAO; 2016.

36. FAO: A resource guide to method selection and application in low resource settings. pp. 152. Rome2018:152.

37. Women's Dietary Diversity Project Study Group: Development of a Dichotomous Indicator for Population-Level Assessment of Dietary Diversity in Women of Reproductive Age. Curr Dev Nutr 2017, 1.

38. Central Statistical Agency (CSA), ICF.: Ethiopia Demographic and Health Survey. Addis Ababa, Ethiopia and Rockville, Maryland, USA:: CSA and ICF; 2016.

39. Rutstein SO, Johnson K: The DHS wealth index. In DHS Comparative Reports No 6. Calverton, Maryland, USA: ORC Macro; 2004.

40. Zou G: A modified poisson regression approach to prospective studies with binary data. Am J Epidemiol 2004, 159:702-706.

41. Yelland LN, Salter AB, Ryan P: Performance of the modified Poisson regression approach for estimating relative risks from clustered prospective data. Am J Epidemio/ 2011, 174:984-992.

42. Noor RA, Abioye Al, Ulenga N, Msham S, Kaishozi G, Gunaratna NS, Mwiru R, Smith E, Dhillon CN, Spiegelman D, Fawzi W: Large -scale wheat flour folic acid fortification program increases plasma folate levels among women of reproductive age in urban Tanzania. PLoS One 2017, 12:e0182099.

43. Matsuzaki M, Haruna M, Ota E, Sasaki S, Nagai Y, Murashima S: Dietary folate intake, use of folate supplements, lifestyle factors, and serum folate levels among pregnant women in Tokyo, Japan. $J$ Obstet Gynaecol Res 2008, 34:971-979.

44. Ferreira AF, Giugliani R: Consumption of folic acid-fortified flour and folate-rich foods among women at reproductive age in South Brazil. Community Genet 2008, 11:179-184.

45. Monteagudo C, Mariscal-Arcas M, Palacin A, Lopez M, Lorenzo ML, Olea-Serrano F: Estimation of dietary folic acid intake in three generations of females in Southern Spain. Appetite 2013, 67:114118. 
46. Kancherla V, Koning J, Biluts H, Woldemariam M, Kibruyisfaw Z, Belete A, Koning M: Projected impact of mandatory food fortification with folic acid on neurosurgical capacity needed for treating spina bifida in Ethiopia. Birth Defects Res 2021, 113:393-398.

47. Kancherla V, Chadha M, Rowe L, Thompson A, Jain S, Walters D, Martinez H: Reducing the Burden of Anemia and Neural Tube Defects in Low- and Middle-Income Countries: An Analysis to Identify Countries with an Immediate Potential to Benefit from Large-Scale Mandatory Fortification of Wheat Flour and Rice. Nutrients 2021, 13:244.

48. Miller BDD, Welch RM: Food system strategies for preventing micronutrient malnutrition. Food Policy 2013, 42:115-128.

49. Haidar J, Melaku U, Pobocik R: Folate deficiency in women of reproductive age in nine administrative regions of Ethiopia: an emerging public health problem. South African Journal of Clinical Nutrition 2016, 23:132-137.

50. Belgnaoui S, Belahsen R: Nutrient intake and food consumption among pregnant women from an agricultural region of Morocco. International Journal of Food Sciences and Nutrition 2006, 57:19-27.

51. Maugeri A, Barchitta M, Agrifoglio O, Favara G, La Mastra C, La Rosa MC, Magnano San Lio R, Panella M, Cianci A, Agodi A: The impact of social determinants and lifestyles on dietary patterns during pregnancy: evidence from the "Mamma \& Bambino" study. Ann Ig 2019, 31:81-89.

52. Adubra L, Savy M, Fortin S, Kameli Y, Kodjo NE, Fainke K, Mahamadou T, Le Port A, Martin-Prevel Y: The Minimum Dietary Diversity for Women of Reproductive Age (MDD-W) Indicator Is Related to Household Food Insecurity and Farm Production Diversity: Evidence from Rural Mali. Curr Dev Nutr 2019, 3:nzz002.

53. Mekonnen DA, Talsma EF, Trijsburg L, Linderhof V, Achterbosch T, Nijhuis A, Ruben R, Brouwer ID: Can household dietary diversity inform about nutrient adequacy? Lessons from a food systems analysis in Ethiopia. Food Security 2020, 12:1367-1383.

54. Jemal K, Awol M: Minimum Dietary Diversity Score and Associated Factors among Pregnant Women at Alamata General Hospital, Raya Azebo Zone, Tigray Region, Ethiopia. J Nutr Metab 2019, 2019:8314359.

55. Oumer M, Taye M, Aragie H, Tazebew A: Prevalence of Spina Bifida among Newborns in Africa: A Systematic Review and Meta-Analysis. Scientifica (Cairo) 2020, 2020:4273510.

56. Tadesse AW, Kassa AM, Aychiluhm SB: Determinants of Neural Tube Defects among Newborns in Amhara Region, Ethiopia: A Case-Control Study. Int J Pediatr 2020, 2020:5635267.

57. Maffoni S, De Giuseppe R, Stanford FC, Cena H: Folate status in women of childbearing age with obesity: a review. Nutr Res Rev 2017, 30:265-271.

58. Krishnaswamy K, Madhavan Nair K: Importance of folate in human nutrition. Br J Nutr 2001, 85 Suppl 2:S115-124.

59. Ohrvik VE, Witthoft CM: Human folate bioavailability. Nutrients 2011, 3:475-490.

60. Gashu D, Stoecker BJ, Adish A, Haki GD, Bougma K, Marquis GS: Ethiopian pre-school children consuming a predominantly unrefined plant-based diet have low prevalence of iron-deficiency 
anaemia. Public Health Nutr 2016, 19:1834-1841.

61. Tuokkola J, Luukkainen P, Kaila M, Takkinen HM, Niinisto S, Veijola R, Virta LJ, Knip M, Simell O, Ilonen J, Virtanen SM: Maternal dietary folate, folic acid and vitamin D intakes during pregnancy and lactation and the risk of cows' milk allergy in the offspring. Br J Nutr 2016, 116:710-718.

62. Eck LH, Klesges RC, Hanson CL, Slawson D, Portis L, Lavasque ME: Measuring short-term dietary intake: development and testing of a 1-week food frequency questionnaire. J Am Diet Assoc 1991, 91:940-945.

63. Resnicow K, Odom E, Wang T, Dudley WN, Mitchell D, Vaughan R, Jackson A, Baranowski T: Validation of three food frequency questionnaires and 24-hour recalls with serum carotenoid levels in a sample of African-American adults. Am J Epidemiol 2000, 152:1072-1080.

\section{Figures}

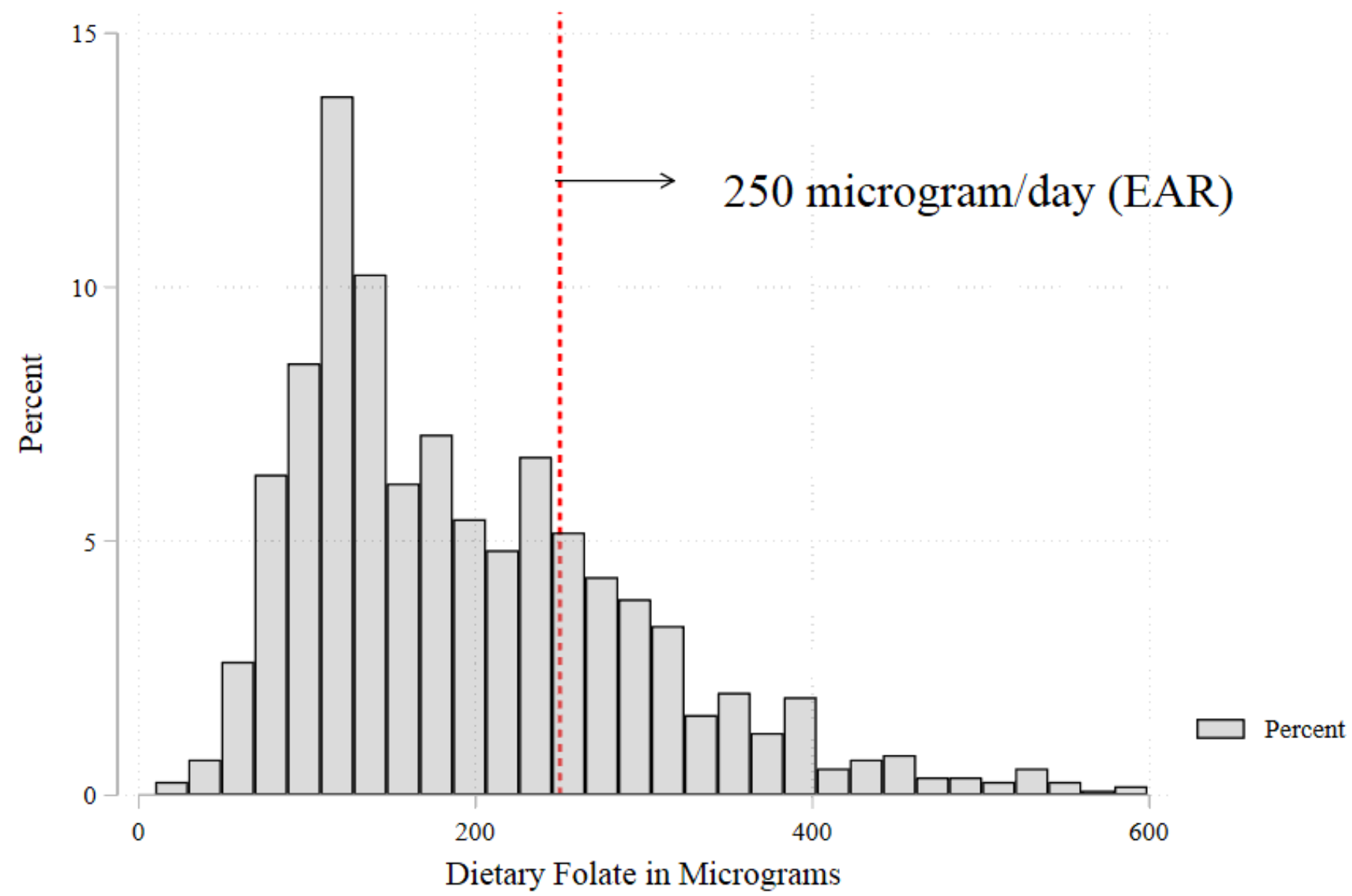

Figure 1

Usual dietary Folate consumption among women of reproductive age, Kersa, Eastern Ethiopia, 2019 


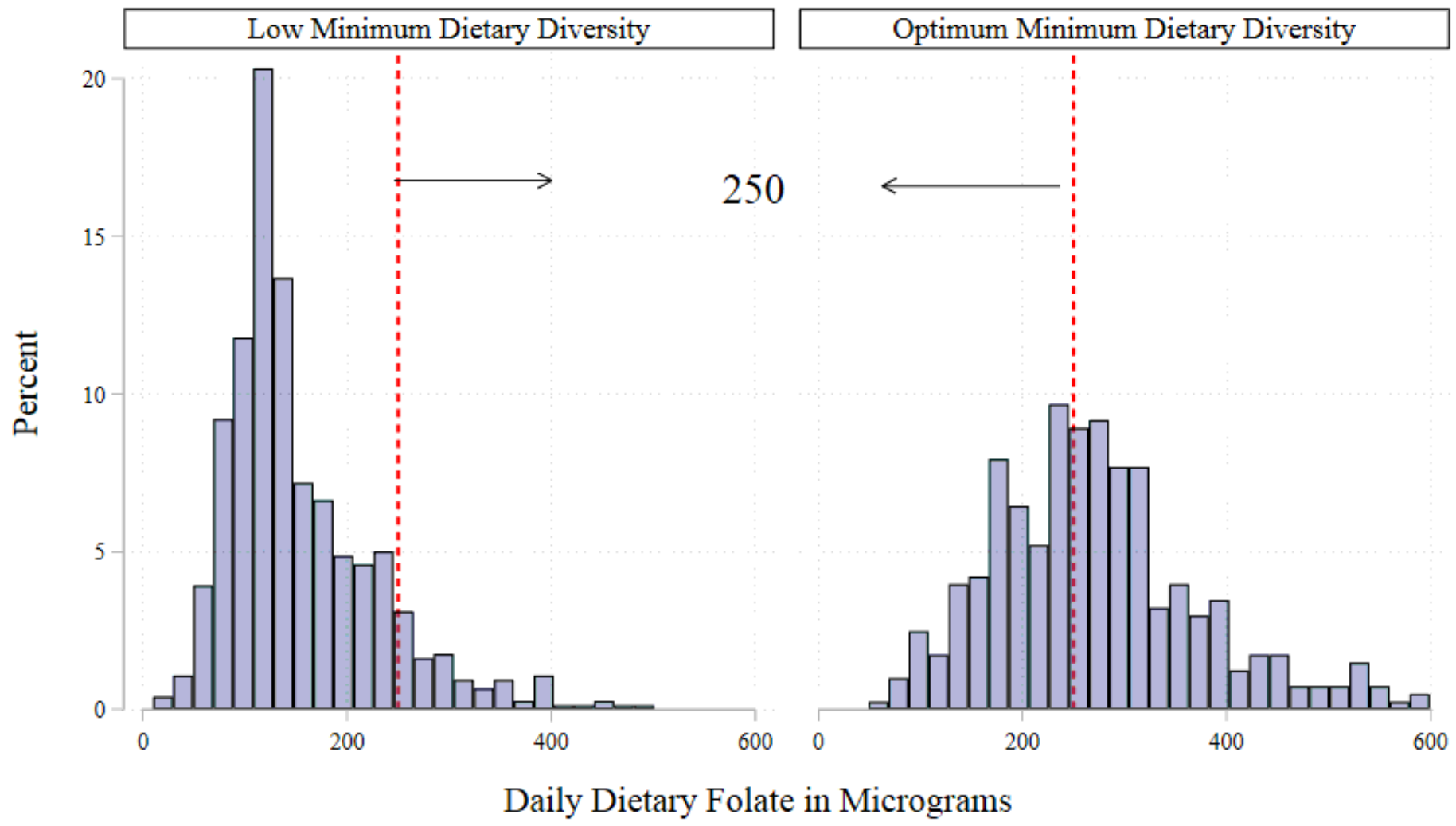

Figure 2

Total Dietary Folate Consumption by Minimum Dietary Diversity among women of reproductive age, Kersa, Eastern Ethiopia, 2019 